\title{
Assessment of Adherence and Self-Efficacy of People with VIH/ AIDS
}

\section{Silva CGS, Silva PE and Alchieri JC*}

Post-Graduation in Health Sciences, Federal University of Rio Grande do Norte-UFRN, Brazil

*Corresponding author: Joao Carlos Alchieri, Post-Graduation in Health Sciences, Federal University of Rio Grande do Norte-UFRN, Natal, RN-Brazil, Email: jcalchieri@gmail.com

\section{Research Article}

Volume 5 Issue 4

Received Date: October 05, 2020

Published Date: November 03, 2020

DOI: $10.23880 /$ pprij-16000247

\section{Abstract}

Adherence to antiretroviral therapy (ART) for VIH/AIDS is essential to maintain the health status of the person living with VIH/AIDS. How people experience, think, motivate, and behave can be determined by beliefs of effectiveness. Such beliefs produce diverse effects through four main processes: cognitive, motivational, affective, and selective. In this study, the possible relationship between adherence and self-efficacy was assessed, the role of the patient as a decisive factor in maintaining adherence for antiretroviral treatment. CEAT-VIH (measuring compliance) and the Self-Efficacy Expectation Scale were used to follow the Antiretroviral Prescription. There were 53 VIH/AIDS patients, men and women, whose regression analysis revealed a relationship between the capacity for self-efficacy and the level of adherence and significance. The analysis showed that the role of the patient during his treatment is important for the success of the treatment and maintenance of adherence based on self-efficacy.

Keywords: Adherence; Self-efficacy; Therapy; Antiretroviral; AIDS

\section{Introduction}

\section{Assessment of Adherence and Self-efficacy of People with VIH/AIDS}

Adherence to antiretroviral therapy for VIH/AIDS (ART) is essential for maintaining the health status, reducing the risk of virus transmission, and minimizing viral resistance to the drug. Young people living with VIH often have little participation in the treatment, describe low self-efficacy, depression, unsuccessful coping styles, minimally efficient social and cognitive support, these being considered predictive aspects of low adherence [1].

Defined as the discipline of each person to follow pharmacotherapy and make changes in their lifestyle according to guidelines given by the doctor. Health professionals converge on the patient the responsibility to adhere to the treatment, but the awareness of the disease and the treatment are causally related. Ignoring the way, the patient perceives himself in relation to his treatment, the sociocultural context and the view of the health-disease process, can make it difficult to understand the real reasons and the adequate adherence [2].

Understanding the consequences of not maintaining medication use and lower than expected adherence rates are decisive factors for successful treatment. Adherence levels below $95 \%$, between 53 and $74 \%$, can result in a decrease in viral load when regimens with the most potent drugs used today are part of the range of treatment options. However, the best rates of viral suppression are observed when there is a minimum adherence of $95 \%$ of medication taking $[3,4]$.

In order to modify a problem situation, interventions aimed at improving adherence to VIH/AIDS treatment are structured, using theoretical models, among which stand out, cognitive models, where the acceptance that attitudes 
and beliefs are shared, as well as, the possibilities of future threatening health events and the positive results of a treatment or intervention are the main determinants of behavior in relation to health. These can be understood in sub-themes of health beliefs and protection motivation, such as: cognitive-social, where self-efficacy and expectation of results, are behavioral skills based on informationmotivation [4].

Perceived self-efficacy is defined as a person's belief in their ability to produce designated levels of performance that influence events that affect vital aspects. Effective beliefs determine how people feel, think, motivate, and behave. Such beliefs produce these diverse effects through four main processes, which are: cognitive, motivational, affective, and selective [5].

In this study, the possible relationship between adherence and group self-efficacy and the patient's role as a decisive factor in maintaining adherence and competing for antiretroviral treatment was evaluated [6-9].

In a study conducted at the Specialized Assistance Service (SAS) for people living with VIH/AIDS, at Hosp. Giselda Trigueiro (AIDS clinic in Rio Grande do Norte, Brazil) [10-12]. Two instruments were used to assess adherence to treatment (CEAT-VIH and the Self-Efficacy Expectation Scale in Following the Antiretroviral Prescription) in a group of 53 patients (men and women) in medical consultation at AIDS clinic $[13,14]$.

Inclusion criteria were, being a volunteer, minimum age 18 years old, being in regular clinical care, having a body weight over $30 \mathrm{~kg}$ and being in one of the three conditions regarding the duration of ART use (less than 1 year ago less than 5 years and for more than 5 years). Individuals who did not meet the conditions described above, pregnant women and those who did not want to continue the study, or who had cognitive deficits that prevented the understanding of the study were excluded.

The study was approved by the Research Ethics Committee of Hospital University Onofre Lopes - HUOL/ FURN, (no CAAE 47729615.8.0000.5292). Two stages were developed, where the first comprised data collection and analysis of medical records for secondary data (monitoring treatment with data from the last collection of LTCD $4+$ and Viral Load) and the second stage, the interviews focused on intervention. The sample comprised 53 VIH/AIDS seropositive patients, men (53\%) and women (47\%). The captured patients had an average of 44.7 years of age and $66.4 \mathrm{~kg}$ of body weight. As for the educational level, $45.3 \%$ have incomplete elementary education, which shows that the researched group lives in a situation of few financial resources (only 1.2 minimum wages on average), with little access to educational resources. As for the duration of ART use, patients were distributed in 9.4\% with less than 1 year of ART, $32.1 \%$ for less than 5 years in use, and $58.5 \%$ with more than 5 years of ART.

Graph 1 shows the behavior of the level of adherence and the capacity for self-efficacy of the 53 patients with $\mathrm{VIH}$, showing a positive linear behavior regarding the subject's capacity for self-efficacy in continuing with his treatment, an upward relationship between the level of adherence and the capacity of the patient to be efficient in their care.

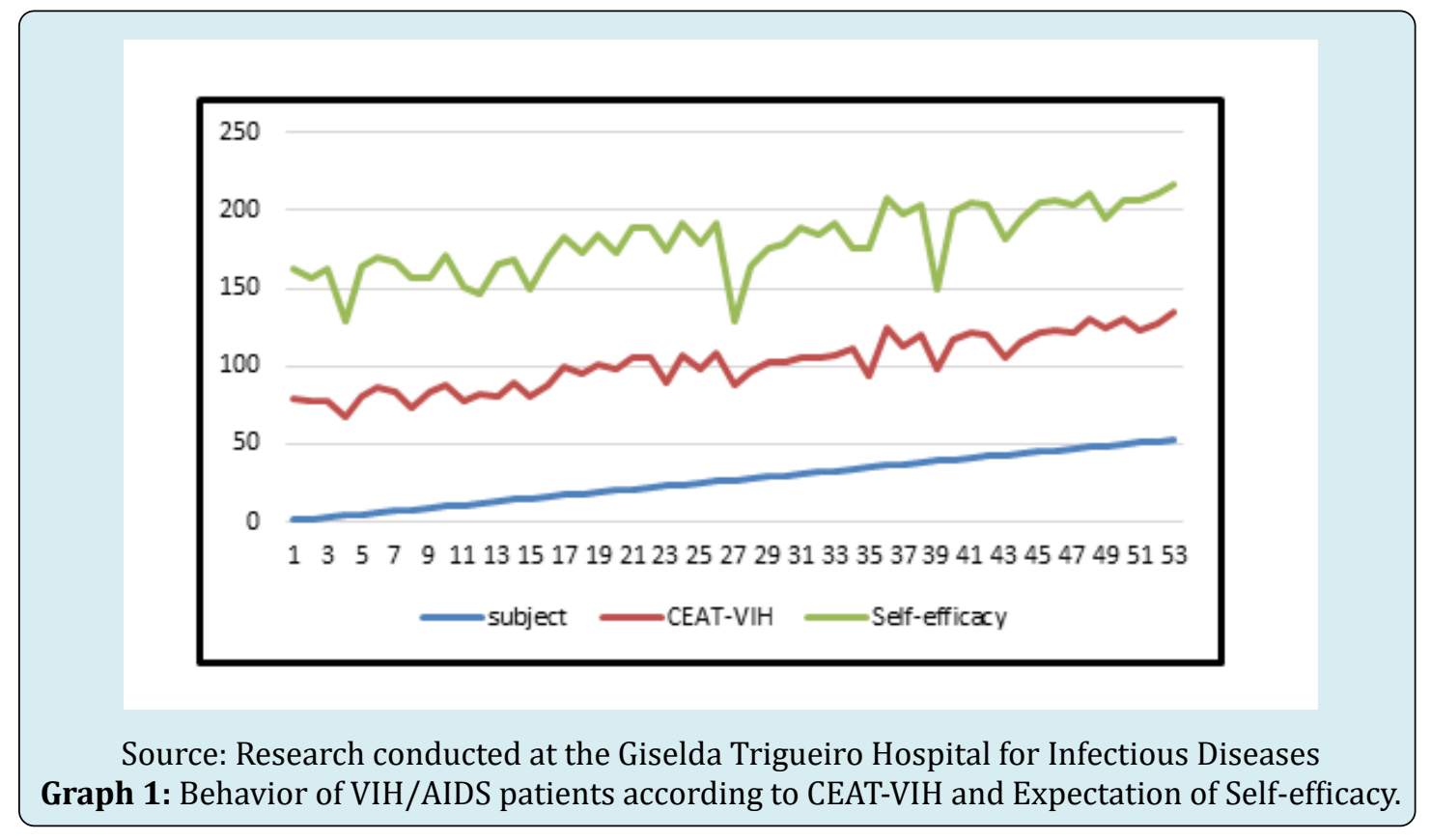


An expert doctor checked the biological markers for VIH (LTCD4 + / CD8 + and Viral Load) [6] and found that 84.9\% of the participants were promising against $15.1 \%$ who were not promising in antiretroviral treatment in this sample, reinforcing the instrumental assessment developed by the scales. It should be noted that being promising in treatment refers to the efficiency of the patient in taking the medication, but it does not define his level of adherence.
The results (Table 1) of the regression analysis, which revealed a relationship between the capacity for self-efficacy and the level of adherence ( $p$-value <0.001). The level of adherence explains $32 \%$ of the self-efficacy of VIH patients. The CEAT-VIH and Expectation of Self-efficacy have items that predominantly refer to the performance of the VIH patient, as a protagonist in their treatment at the $5 \%$ significance level.

\begin{tabular}{|c|c|c|c|c|c|}
\hline & Coefficient & Standard error & $\mathbf{t}$ & $\mathbf{R}^{2}$ & Value -p \\
\hline Intercept & 23.15 & 11.43 & 2.03 & \multirow{2}{*}{0.32} & 0.048 \\
\hline Residue & 0.742 & 0.15 & 4.86 & & $<0.001$ \\
\hline
\end{tabular}

Table 1: Regression analysis of patients with VIH / AIDS $(n=53)$ regarding the Expectation of Self-efficacy and Adherence measured by the CEAT-VIH Instrument, at the significance level of $5 \%$.

Shows the results (Table 2) of the t-test and analysis of variance, used to verify whether there is a difference between the average capacity of the patients surveyed in reaching levels of adherence to the CEAT-VIH instrument and the Expectation of self-efficacy. Variables such as: Have you ever stopped taking your medication? If you ever felt better, did you stop taking your medication?; If you ever felt worse after taking your medication, did you stop taking it?; If you ever felt sad or depressed, did you stop taking your medication? How much benefit can the use of these medicines bring you? How do you assess the intensity of side effects related to the use of VIH medications? What assessment do you have of yourself regarding taking VIH drugs? How much difficulty do you have to take the medication?; Since you are under treatment, have you ever stopped taking your medication for a full day, or more than one? that makes up the instrument reveal significant mean differences in terms of the expectation of self-efficacy, at a significance level of $5 \%$.

\begin{tabular}{|c|c|c|c|c|c|}
\hline Variáveis & $\mathbf{N}$ & $\%$ & Mean & $\begin{array}{l}\text { Standard } \\
\text { deviation }\end{array}$ & p-Value \\
\hline \multicolumn{6}{|c|}{ Have you ever stopped taking your medication? } \\
\hline Ever & 0 & 0 & - & - & \\
\hline More than half the time & 0 & 0 & - & - & \\
\hline Approximately half the time & 03 & 5.66 & $62.33^{\mathrm{c}}$ & 14.05 & $<0.001^{1}$ \\
\hline Sometimes & 10 & 18.87 & $86.60^{\mathrm{b}}$ & 8.49 & \\
\hline Not once & 40 & 75.47 & $96.98^{\mathrm{a}}$ & 4.81 & \\
\hline Total & 53 & 100 & & & \\
\hline \multicolumn{6}{|c|}{ If you ever felt better, did you stop taking your medication? } \\
\hline Ever & 0 & 0 & - & - & \\
\hline More than half the time & 0 & 0 & - & - & \\
\hline Approximately half the time & 1 & 1.89 & $61.00^{\mathrm{b}}$ & - & $0.005^{1}$ \\
\hline Sometimes & 1 & 1.89 & $61.00^{\mathrm{ab}}$ & - & \\
\hline Not once & 51 & 96.22 & $93.03^{\mathrm{a}}$ & 9.70 & \\
\hline Total & 53 & 100 & & & \\
\hline \multicolumn{6}{|c|}{$\begin{array}{c}\text { If ever after taking your medication } \\
\text { did you feel worse, did you stop taking it? }\end{array}$} \\
\hline Ever & 0 & 0 & - & - & \\
\hline More than half the time & 0 & 0 & - & - & \\
\hline Approximately half the time & 0 & 0 & - & - & $<0.001^{2}$ \\
\hline
\end{tabular}




\begin{tabular}{|c|c|c|c|c|c|}
\hline Sometimes & 1 & 1.89 & 49.00 & - & \\
\hline Not once & 52 & 98.11 & 93.91 & 8.67 & \\
\hline Total & 53 & 100 & & & \\
\hline $\begin{array}{l}\text { If you ever felt sad or depressed, did you stc } \\
\text { medication? }\end{array}$ & & & & & \multirow{6}{*}{$<0.001$} \\
\hline Ever & 0 & 0 & - & - & \\
\hline More than half the time & 0 & 0 & - & - & \\
\hline Approximately half the time & 1 & 1.89 & $61.00^{\mathrm{b}}$ & - & \\
\hline Sometimes & 4 & 7.55 & $72.75^{\mathrm{b}}$ & 16.60 & \\
\hline Not once & 48 & 90.57 & $95.42^{5}$ & 6.58 & \\
\hline Total & 53 & 100 & & & \\
\hline \multicolumn{6}{|c|}{$\begin{array}{l}\text { How much benefit can the use of these } \\
\text { medicines? }\end{array}$} \\
\hline Nothing & 2 & 3.77 & $85.00^{\mathrm{a}}$ & 8.49 & \\
\hline Little & 1 & 1.89 & $49.00^{\mathrm{b}}$ & - & \\
\hline steady & 2 & 3.77 & $85.00^{\mathrm{a}}$ & 15.60 & \\
\hline Quite & 4 & 7.55 & $92.75^{\mathrm{a}}$ & 10.87 & \\
\hline Much & 44 & 83.02 & $94.41^{\mathrm{a}}$ & 8.33 & \\
\hline Total & 53 & 100 & & & \\
\hline \multicolumn{6}{|c|}{$\begin{array}{l}\text { How do you rate the intensity of side effects related to the use of } \\
\text { VIH medications? }\end{array}$} \\
\hline Very intense & 11 & 20.75 & $87.73^{a}$ & 15.27 & \\
\hline Intense & 6 & 11.32 & $83.83^{a}$ & 14.39 & \\
\hline Moderately intense & 5 & 1.56 & $100.00^{\mathrm{b}}$ & 0.00 & $0.014^{1}$ \\
\hline Slightly intense & 8 & 15.09 & $97.50^{\mathrm{a}}$ & 4.38 & \\
\hline Nothing intense & 23 & 43.39 & $94.97^{\mathrm{a}}$ & 6.75 & \\
\hline Total & 53 & 100 & & & \\
\hline \multicolumn{6}{|c|}{$\begin{array}{c}\text { What assessment do you have of yourself regarding taking VIH } \\
\text { drugs? }\end{array}$} \\
\hline Nothing compliant & 1 & 1.89 & $61.00^{c}$ & - & $0.012^{1}$ \\
\hline Not compliant & 0 & 0 & - & - & \\
\hline Steady & 7 & 13.21 & $85.29^{\mathrm{bc}}$ & 9.30 & \\
\hline Quite & 12 & 22.64 & $93.33^{\mathrm{ab}}$ & 6.43 & \\
\hline Very compliant & 33 & 62.26 & $95.58^{\mathrm{a}}$ & 9.96 & \\
\hline Total & 53 & 100 & & & \\
\hline \multicolumn{6}{|c|}{ How much difficulty do you have to take the medication? } \\
\hline Much difficulty & 1 & 1.89 & $61.00^{\mathrm{b}}$ & - & \\
\hline Difficult enough & 2 & 3.77 & $93.00^{\mathrm{ab}}$ & 4.24 & \\
\hline steady & 3 & 5.66 & $94.00^{\mathrm{a}}$ & 10.39 & $0.037^{1}$ \\
\hline Little difficulty & 9 & 16.98 & $91.67^{\mathrm{a}}$ & 9.39 & \\
\hline No difficulty & 38 & 71.70 & $94.16^{\mathrm{a}}$ & 10.10 & \\
\hline
\end{tabular}




\section{Psychology \& Psychological Research International Journal}

\begin{tabular}{|c|c|c|c|c|c|}
\hline Total & 53 & 100 & & & \\
\hline $\begin{array}{c}\text { Since you are under treatment, have you ever stopped taking } \\
\text { your medication for a full day, or more than one? }\end{array}$ & & & & & \\
\hline Yes & 31 & 58.49 & 89.68 & 12.34 & \\
\hline No & 22 & 41.50 & 97.83 & 4.28 & 0.005 \\
\hline Total & $\mathbf{5 3}$ & $\mathbf{1 0 0}$ & & & \\
\hline
\end{tabular}

Reference: analysis of variance; 2 test $t$ for independent samples

Table 2: Average behavior of the self-efficacy and adherence capacity of VIH patients, using analysis of variance and the $t$ test, $5 \%$ significance level

Self-efficacy is presented as a possible model from the perspective of self-care to achieve excellent levels of adherence (>95\%). The literature points to studies [7-10] that analyze adherence to treatment related to self-efficacy, which suggest that the clinical management of VIH should identify and address, for example, social support, the quality of the information received and the management of the state of mood as a positive support for the self-efficacy of patient. A positive relationship was observed between their levels of adherence and the Expectation of Self-efficacy, as they seek strategies for the patient to develop personal skills and abilities to control the circumstances that may hinder the regular follow-up of drug treatment for VIH [5].

As a possibility to reduce limitations in the present study, relationship between the duration of ART use (less than 1 year, less than 5 years and more than 5 years of treatment) and leveling in groups (without adherence and with adherence), which may prove important in better understanding the participation of the self-efficacy model, as studies [11,12] also demonstrate the time of use of antiretroviral as an important factor, although not a determinant for adherence to treatment. For the present sample, there was a positive relationship between their levels of adherence and the Expectation of Self-efficacy, as they seek strategies for the development of personal skills to control the circumstances that may hinder the regular follow-up of drug treatment for the patient. VIH in question. Since self-efficacy [5] is seen as the central mechanism of actions performed intentionally by the human being.

It is recommended that a study be developed to verify whether there is a relationship between the time of use of ART (less than 1 year, less than 5 years and more than 5 years of treatment) and the individual's ability to develop self-efficacy strategies that contribute to adherence to your treatment. And another recommended study, would be to apply intervention with the use of the Theory of Self-efficacy to those patients who have less than 1 year of treatment, possibly the most critical period after diagnosis, in order to verify, which factors are interfering in this phase of treatment and if the Theory Self-efficacy would favor a change in attitude.

The application of the Theory of Self-efficacy as an intervention, benefits the individual to the extent that it suggests that they can feel responsible for their care. Therefore, becoming an "agent" of one's own care implies saying that it can intentionally influence its functioning and circumstances of life and not just be a product of the environment.

\section{Acknowledgement}

This study was financed in part by the Coordenação de Aperfeiçoamento de Pessoal de Nível Superior - Brasil (CAPES) - Finance Code 001

\section{References}

1. Belzer ME, McDonell KK, Clark LF, Huang J, Olson J, et al. (2015) Acceptability and Feasibility of a Cell Phone Support Intervention for Youth Living with HIV with Nonadherence to Antiretroviral Therapy. Aids Patient Care and STDs 29(6): 338-345.

2. Rocha GM, Bonolo PF, Ceccato MGB (2010) Cap. 2: Adherence to antiretroviral treatment: a systematic review, 2004-2009. In: Brazil, Ministry of Health, Secretariat of Health Surveillance. Department of STD, AIDS, and Viral Hepatitis. Adherence to antiretroviral treatment in Brazil: collection of studies from the ATAR Project. Brasília: Ministry of Health.

3. Tietzmann DC, Béria JV, Santos GM, Mallamann DA, Trombini ES, et al. (2013) Prevalence of Adherence to Antiretroviral Therapy and Associated Factors in Adult Patients from Three Urban Centers of southern Brazil Aletheia 41: 154-163.

4. Basso CR, Helena ETS, Caraciolo JMM, Paiva V, Nemes MIB (2013) Exploring ART Intake Scenes in a Human Rights-Based Intervention to Improve Adherence: A randomized controlled trial. AIDS Behav 17(1): 181-192.

5. Bandura A (1994) Self-efficacy. In: Ramachaudran 


\section{Psychology \& Psychological Research International Journal}

VS (Ed.), Encyclopedia of human behavior. New York: Academic Press 4: 71-81.

6. Ministry of Health (2013) Health Surveillance Secretariat. Department of STD, AIDS and Viral Hepatitis. Technical Manual for the Diagnosis of HIV Infection. Brasilia: 56p.

7. Li l, Lin C, Lee SJ, Tuan LA, Feng N, et al. (2017) Antiretroviral therapy adherence and self-efficacy among people living with HIV and a history of drug use in Vietnam. International Journal of STD \& Aids 28(12): 1247-1254.

8. Swendman D, Ramanathan N, Baetscher L, Medich M, Scheffler A, (2015) Smartphone Self-Monitoring to Support Self-Management Among People Living With HIV: Perceived benefits and theory of change from a mixed-methods randomized pilot study. J. Acquir. Immune Defic Syndr 69(1): 580-591.

9. Costa LS, Latorre MRDD, Silva MH, Bertolini DV, Machado DM, et al. (2008) Validity and Reliability of a self-efficacy expectancy scale for adherence to antirretroviral therapy for parentes and carers of children and adolescents with HIV/Aids. Journal of Pediatrics 84(1): 41-46.

10. Reif S, Proeschold-Bell RJ, Yao J, LeGrand S, Uchara A
(2013) Three types of self-efficacy associated with medication adherence in patients with co-occurring HIV and substance use disorders, but only when mood disorders are present. Journal of Multidisciplinary Health Care 6: 229-237.

11. Inzaule SC, Hamers RL, Kityo C, Rinke de Wit TF, Roura M (2016) Long-Term Antiretroviral Treatment Adherence in HIV-Infected Adolescents and Adults in Uganda: A Qualitative Study. PLOS ONE 12(2): 1-15.

12. Rosenblum M, Deeks SG, Van Der Laan M, Bangsberg DR (2009) The Risk of Virologic Failure Decreases with Duration of HIV Suppression, at Greater than 50\% Adherence to Antiretroviral Therapy. PLOS ONE 4(9): 1-7.

13. Remor E (2013) Systematic Review of the Psychometric Properties of the Questionnaire to Evaluate the Adherence to HIV Therapy (CEAT-VIH). Patient 6(2): 6173.

14. Leite JCC, Drachler ML, Centeno MO, Pinheiro CAT, Silveira VL (2002) Development of a Self-Efficacy Scale for Adherence to Antiretroviral Treatment. Psychology: Reflection and Criticism. 15(1): 121-133. 